\title{
An Analysis of Learning Barriers: The Saudi Arabian Context
}

\author{
Dr. Intakhab A. Khan \\ King Abdul Aziz University Community College, Jeddah, Saudi Arabia \\ E-mail: dr.intakhab@yahoo.com
}

\begin{abstract}
Learning and teaching are quite interrelated. Teaching can't take place unless the target students learn. Thus, teaching is a bi-polar activity. Learning barriers or causes of learning difficulties are quite common in an educational setting. But, when it comes to a very adverse effect it becomes crucial and unavoidable. There are different kinds of factors in general. The following barriers are some of those that are very influential: social, cultural, parental, attitudinal, motivational, psychological, personal and pedagogical factors. Pedagogical factors in particular include teachers, action researches, teaching strategies, teaching resources and administration.

The present paper focuses on the following: motivation of the students and the teachers, dedication and commitment, teacher's role, teacher's characteristics, teaching strategies, training and professional development. The case of Saudi Arabia is very important for many reasons. The government is spending a lot of money on education. But, the achievement of learning is not up to the mark. Therefore, it is essential to study the effect of the above mentioned factors on academic achievement which will consequently lead to the possible evolution of some feasible and compatible teaching-learning strategies. Such strategies are expected to minimize the chance of waste, and yield maximum educational output in Saudi Arabia in particular.
\end{abstract}

Keywords: Barriers, Factors, Socio cultural factors, Psychological factors, Pedagogical factors, Teacher factor, Motivation

\section{Learning Barriers}

Learning is a complex process. It involves many sub-processes. Learning and education are quite interrelated, and education is an interdisciplinary subject. In spite of the fact that an institution usually takes into account all the necessary parameters to make the educational process a success, there are situations in which teaching-learning fails. In this connection, we are always reminded of certain known and unknown barriers that act as hurdles or obstacles on the way to education. Such barriers to learning are also very common and we can come across to most of these in our day to day teaching activities. However, situations may vary. Barriers among students may include those factors that can easily be minimized or removed. But, in certain cases, the barriers are almost impossible for some reasons such as natural disability or limitations.

In the present case, the target learners are those who are just like other students of other parts of the world. Yet, they face many barriers while learning. Barriers to learning for students in general may be personal, emotional, economic, attitudinal or even organisational. The initiatives to recognise diversity within the student population and to understand the dynamics of learning especially the aspects of individual differences are expected to help the teachers/institutions to diagnose the barriers to learning in general, and minimize or remove them if possible.

The adjustments a teacher makes for learner differences should occur for all students. Curriculum materials should be diverse, selective and appropriate including high tech material, e-learning resources, rather than focusing on traditional textbook(s). Barriers to participation in higher education can be found important for many learner groups. One has to remember the principle of four 'As' when one is serious about how to remove or minimise the barriers: Access, Awareness, Acceptance and Appreciation.

A learner has many responsibilities that must be balanced against the learning needs. Because of these responsibilities, he may have barriers against participating in learning. Some of these barriers include (a) lack of time, (b) lack of confidence, (c) lack of information about opportunities to learn, (d) scheduling problems, (e) lack of motivation, and (f) "red tape"(Lieb,1991).

If the learner does not see the need for the change in behavior or knowledge, it is likely that a barrier exits. Likewise, if the learner can not apply learning to his/her past experiential or educational situations, the teacher will have to overcome the barriers of learning. There is no denying the fact that Education is an important institution of socialization, but many critics see formal education as biased in favour of the status quo. We must consider, as Gary Gardner (2001) has done, whether education today "is capable of standing outside of society and critiquing it in a way that creates a worldview grounded in sustainability." 


\section{General Barriers to Participation in Education}

Educators distinguish between perceived barriers and actual barriers to adult learning and form these into three categories: institutional barriers (practices that exclude or discourage adults), "situational barriers (arising from one's life situation), and dispositional barriers (attitudes and perceptions about oneself as learner),"observes Conn (1995).

Learning barriers have roots. These don't appear abruptly. These may start affecting from early stages, and continue though out the educational processes. Thus, psycho social analysis of such barriers may enable an instructor or educationalist to go deep into any such educational phenonmenon, and be ready to cope with.

\section{Lack of Motivation-Focused Teaching}

Motivation is also of great importance in raising the tendency towards individual learning. According to Weiqiao Fan ( 2009), 'It is one of the basic conditions which achieve the goal of the learning process, the learning ways of thinking, the formation of attitudes and values, the collection of information and the problem solving'.

As Moore (1989) hypothesized student-instructor interaction was very important to both students and instructors. Both unidirectional (websites, email, Streaming Video) and bi-directional (email, e-chatting, telephone, meetings etc) interactions with the content and with instructors were used by students in synchronous and asynchronous modes throughout the course of study Technologies like Streaming Video have shown mixed success in facilitating student-instructor interactions, and should be supplanted with more functional technologies in the future in order to motivate the learners.

Richards (2001) is of the opinion that 'Learning skills allow the learner to acquire patterns of behavior that will be associated with him during the course of study. These patterns become study habits and will have a relative stability adjective with respect to the learner'. Nneji (2002) opines that students in the university have the responsibility to identify their goals and pursue strategies that lead to the achievement of these objectives. Therefore, some strategies should include the study habits which lead to develop the composition of the student's knowledge.

The fact that without any motivation nothing can be done properly is absolutely true. Since teaching is a profession, it requires genuinely motivated and appropriately dedicated teachers to carry out the teaching tasks and lead the learners to the right path- the path of success. In my humble opinion, there are two types of teachers: teachers by chance and teachers by choice. If a teacher is in the teaching profession just by chance, he won't be able to serve the learner community as he should. It is simply because of the reason that to him teaching is just a means of earning livelihood- an occupation.

\section{Faulty Transfer of Learning}

If one is not able to apply learning to solve problems or to change behaviour there is a fair chance of the presence of another type of learning barrier. Parker and Parikh (1999) present Prochaska's trans- theoretical model of change in adult behaviour as a framework for needs assessment, course design, and evaluation that helps explain why learning initiatives do not always change performance. According to the Prochaska model, change is a gradual five-step process; if learners are not ready to change, or if the offering does not match their stage of readiness, they will not be able to transfer their learning to effect change in their behaviour. In addition, Program content might focus on irrelevant knowledge instead of needed skills and attitude changes, especially for participants confronting unsupportive family members or colleagues and peers', observes Caffarella (1994).

It has been noticed that problems like transfer of learning are not only faced by younger students. They are taught many things and skills but in the end, they fail to transfer to their day-to-day lives, and we often forget to help children make connections between their new learning and what they already know. Thus, it becomes the teacher's responsibility to diagnose such problems and extend help to overcome if possible.

\section{Inappropriate target Curriculum}

Curriculum in general and syllabi in particular always play inevitable roles in the entire process of learning in an educational system. Therefore, the teaching/learning material (courses) should be properly designed in accordance with the social need and national demand. And, the administration must try to facilitate the learning process by all means especially the teachers. It must be ensured that the maximum utilization of even minimum resource is well considered to be suitably implemented.

\section{Learning barriers in Saudi Arabia:}

As mentioned above, learning barriers are common phenomena. Saudi Arabia is no exception to it. In spite of the fact that the Saudi government is spending a lot of money on educational sector in the form of hiring teachers, infrastructural base, curricular development, research and training, there remain learning barriers. Therefore, it is the 
prime responsibility of the teacher/educator to explore the causes of existing barriers, and find possible solutions so that the teaching/learning can smoothly take place for the ultimate growth and development.

The following barriers are some of those that need to be looked at in the case of Saudi educational setting: linguistic barrier, motivation of the students and the teachers, dedication and commitment, teacher's role, teachers' role and characteristics preparedness, teaching strategies, training and professional development.

Linguistic barrier has been identified as the most crucial barrier in the tertiary education system in Saudi Arabia. English in particular poses greater problems for the target learners. Most students fail to learn due to lack of motivation and vice versa. In this connection, Gardner et al (1985) proposed that the motivated individual is one who wants to achieve a particular goal and experiences satisfaction in the activities in achieving this goal. Gardner further stated that motivation influences language achievement as well as experiences in formal and informal language context influence attitudes and motivation. Gardner and MacIntyre (1991) are of the opinion that integrativeness reflects a positive interest towards the other language or group in general.

Since learning a language involves associating with another cultural group, Gardner and MacIntyre propose that the motivation to learn the language could involve attitudes toward that community and culture. They also say that attitude toward the learning situation play a role in the language- learning situation. This may involve attitude toward the instructor, class, textbooks, language laboratory etc.

Gordon (1980) found that language attitude was the best indicator of English achievement among school students followed by attitude towards the learning situation. Lett and O'mara (1990) did a similar project and found motivation as a factor in achievement even among military personnel. Bartley (1969) similarly found that those who dropped out of language study had significantly lower aptitude scores and less positive attitudes than students who continued their studies.

Hashem A. Alsamadani (2009) investigated into the learning problems with special reference to reading. Reading is said to be an important component of learning/teaching. So the initial issue of learning is basically related to reading.

Learning process has a close connection with reading, and in order to read effectively the role of schema is inevitable. In the case of Saudi learners, the theory of schema is very relevant as this theory is found closely related as most students are unable to read in English, or they are not willing to read any text in English. According to "schema theory," the reader may misunderstand the new material, ignore it, or revise schemata to validate the new information given within the text when it does not fit into his own schemata (Rumelhart, 1980). Carrell (1987) created the divisions of schemata into content schemata and formal schemata. The former is background knowledge about the content which helps the reader understand and remember more than someone who is less familiar with the topic (Carrell, et al.,1983). Formal schemata describe the reader's expectations about how different textual information will fit together and in what order they will appear.

Another factor that seems to be important in the English language teaching and learning situation in Saudi Arabia is language anxiety. Ender and Okada (1975) and Eysenck (1979) describe language anxiety as the apprehension experienced when a situation requires the use of a second language with which the individual is not fully proficient. This, they claim, makes the individual to react in a nervous manner when speaking, listening, reading and writing in the second language. The negative effect of language anxiety in second language has also been shown in the studies of Gardner Smythe, Clement \& Gilksman, (1976), Trylong (1987) and Young (1986) which reports correlations between scores on an oral proficiency interview and language anxiety.

\section{Barriers to Adult Learning}

Cantor $(1992$, p.39) pointed out that the adults have different barriers than children on their way to learning. Some of these potential barriers might include:

- $\quad$ many other responsibilities (families, careers, social commitments)

- $\quad$ lack of time

- lack of money

- $\quad$ child care

- $\quad$ scheduling problems

- $\quad$ transportation problems

- $\quad$ insufficient confidence

- $\quad$ having to learn, if told, but not interested or ready 
If we analyse the above mentioned barriers in the case of Saudi Arabia, the learners usually have family responsibilities especially of mother, but, they don't lack time. Most of them have sufficient money. They are not supposed to do any childcare services as in most houses there are maids and servants/caretakers to assist the whole family. However, Saudi students are negatively affected by scheduling issues. Transportation is also not a problem for most of them. They usually drive their own cars, or dropped by fathers or drivers, and in the worst case, they come in one car with their mates in a group. It is very rare that they lack confidence, and there is a very little pressure from society, parents or even their families.

Motivation: Adults typically, have different motivations for learning than children such as those pointed out by Cantor (1992, 37-38):

- to make or maintain social relationships,

- to meet external expectations-the boss says you have to upgrade a specific skill to keep your job,

- learn to better serve others,

- professional advancement,

- escape or stimulation,

- $\quad$ pure interest.

Instructors should be aware of the possible motivation behind their students' enrollment and retention. Then they can better shape the instructional materials to catch learners' attention. It has been noticed that 'Motivation' is perhaps the most important requirement for the achievement of the targets of teaching/learning.

In the case of Saudi Arabia, it has been found that neither teachers nor students are properly motivated towards educational goals. However, exceptional cases exist. Interestingly enough, the institutional administration try to motivate both the teachers and the learners from time to time. For teachers both materialistic and non-materialistic incentives are also usually provided by the government. The students also get stipend at tertiary level to create and retain motivation among them.

The issue of dedication and commitment is not only related to the educational sector of Saudi, it is a common problem that exists all over the world. A teacher without dedication and commitment is surely unprofessional. For many 'Teaching' is only an occupation, but the fact is that it is the noblest profession. The roles of the teacher should well be identified and the teacher should act in the educational system accordingly. For example, the teacher is a planner, curriculum designer, motivator, assessor, instructor, and above all a facilitator. Therefore, he is the first and foremost responsible person to think about his roles and do the needful.

Most of the teachers in Saudi (local or international) are not found well prepared while going for teaching as they have no ready lesson plans or even scheme of work ( sow). In addition, some of them are not very experienced or equipped to deal with arising situations in class room settings which they haven't come across.

\section{Professional development of teachers}

The training of teachers is always needed for effective teaching. It is a controversial issue whether a teacher is born or made. But, there is no controversy over the issue having some innate traits that can be developed into a very competent and equipped teacher who can prove him to be a precious resource for the society and nation.

In case if a teacher has no formal pre-service teacher training, he can always develop him by attending some in-service training programs. If he is hesitant to do such training courses, at least he is advised to undergo professional development programs in order to be update and equipped.

It has been noticed that most Saudi teachers join teaching profession after having teacher training, but there are many others who have neither in-service or pre service training for teaching. Interestingly enough, such teachers are not at all interested in doing any development programs for many reasons.

\section{Some fruitful strategies}

There are many strategies to cope with the learning barriers. The barriers may be related to pre-admissions or post admissions. Most of the students in Saudi Arabia are found lost in the world of imagination during the lectures. They are sometimes affected by emotional disturbances as well. The teacher being a friendly person can deal with some sort of such problems if he really wishes to.

\section{Handling Emotional Barriers}

A positive teacher- student relationship could help prevent the student from exclusion. The following strategies may be helpful in enhancing the child's learning experience in Further Education. 
The educational philosophy of 'every child matters' obviously leads to prosperity of the nation as well as the individuals. Thus, it is important to evolve appropriate strategy to deal with the situations like these in which the same precious child is in trouble.

\section{Coping with linguistic barriers}

It has been generally noted that most of the Saudi learners face linguistic barrier at tertiary level of education. Since English is the medium of instruction, and the target learners' background seems to be quite humble, they are often scared of learning a subject of study in English in general and studying English in particular. Sometimes they dare learning, but English appears as one of those barriers that they are even afraid to handle. The teachers can play very important role in motivating the learners and minimize the effect of linguistic barrier.

\section{Dealing with indifferent parental attitude}

Negative parenting styles are likely to pose a threat to educational growth. The teacher has to bridge the gap between the indifferent parenting and careful teacher behavior. It is blamed generally that in KSA most parents are found indifferent towards education of their children probably due to the idea that perhaps it is the only responsibility of the government to promote education. The parents especially fathers in Saudi are not much worried about their children's education or future career. Thus, the teacher is supposed to play the role of a guardian or father in order to to motivate and guide their students.

\section{Taking care on unnecessary drop outs}

An effective teacher is supposed to ensure the child's success, and appreciate his efforts. In order to do so, he is supposed to have realistic expectations, clear objectives, give importance to even minor achievements, value the opinion of each precious child, display the student's work on boards or wall magazines, give options, facilitate independent learning for skill development, use positive reinforcement techniques etc.

\section{Coping with the students with economic barriers}

At tertiary level, most students get stipends, therefore, economic barrier does not seem to play any important role. At school levels as well, most of the families are able to provide education as the education is free in Saudi. Thus, the most crucial factor (money) in the countries like India or even USA is not the case in Saudi Arabia. The government facilitates its people to any extent that is feasible for the promotion of education.

\section{Conclusions}

Learning barriers are as crucial as learning or education. It is because of the fact that most individuals or institutions fail to achieve the educational targets basically due to some extraneous or intervening variables within the educational system. Learning barriers are not farfetched ideas rather these are as common as teaching-learning situations in day to day educational/pedagogic activities. Therefore, it seems imperative for policy makers, planners, curriculum designers, pedagogues and administrators to take learning barriers into considerations so that a proper diagnosis of the barriers, their types can be developed to minimize or remove such barriers if possible.

Most institutions in Saudi in general and language centres in particular face the cases of such issues. English as a medium of instruction creates great difficulties to most of the target learners. Therefore, it is essential to deal with such variables to yield maximum educational output.

\section{References}

Bartley, D.E. (1969). A pilot study and attitude factor in language dropout. California journal of Educational Research, 20, 48-55.

Caffarella, R. S. (1994). Planning programs for adult learners. A practical guide for educators, trainers, and staff developers. San Francisco: Jossey-Bass.p.93

Cantor, Jeffrey A. (1992). Delivering Instruction to Adult Learners. Toronto: Wall \& Emerson. (pp. 35-43.)

Carrell, P. (1983). Some Issues in studying the role of schemata, or background knowledge in second language comprehension. Reading in a Foreign Language, 1, 81-92.

Carrell, P. (1987). TESOL Quaterly.VOL.21,No.3,Sept., pp.461-481.

Conn, S. (1995). When the Earth hurts, who responds? In T. Roszak, M. Gomes, \& A. Kanner (Eds.), Ecopsychology: Restoring the Earth, healing the mind (pp. 156-171). San Francisco: Sierra Club.

Ender, N. S \& Okada, M. (1975). A multidimensional measure of trait anxiety; the S-R Inventory of general trait anxiousness, Journal of Consulting and Clinical Psychology, 43, 319-29. 
Eysenck, M.W. (1979). Anxiety, learning, and memory; a reconceptualisation. Journal of Research in Personality, $13,363-85$

Gardener, R.C., Lalonde, R.N \& Moorcroft, R. (1985). The role of attitudes and motivation in second language learning: correlation and experimental considerations. Language learning, 35, 207-27.

Gardener, R.C. \& Mac Intyre, P.D. (1991). An instrumental motivation in language study: who says it isn't effective? Studies in Second Language Acquisition, 13, 57-72.

Gardner, G. (2001). Accelerating the shift to sustainability. In L. Starke (Ed.), State of the world 2001 (pp. 189-206). The World watch Institute. New York: W. W. Norton.

Gardner, R.C, Smythe, P.C, Clement, R \& GilksmanI, L (1976). Second Language Acquisition: a social psychological perspective. Canadian Modern Language Review, 32, 198-213.

Gordon, M.E. (1980). Attitudes and motivation in second language achievement: a study of primary school students learning, English in Belize, Central America. Unpublished Doctoral dissertation, University of Toronto.

Hashem, A. A. (2009). The Relationship between Saudi EFL College-Level Students' Use of Reading Strategies and Their EFL Reading Comprehension. Ph.D.diss. Ohio Univ.

Lett, J \& O'mara, F. E. (1990). Predictors of success in an intensive language learning, context: correlates of language learning, at the Defense Language Institute Foreign Language Center. In T.S. Parry \& C.W. Stansfield (eds) Language aptitude reconsidered, 222-260. Englewood Cliffs, N.J; Prentice Hall Regents.

Lieb, S. (1991). Adult learning principles. Retrieved April 28, 2005, from http://honolulu.hawaii.edu/intranet/committees/FacDevCom/guidebk/teachtip/adults-2.htm.

Moore, M. G. (1989). Three types of interaction. The American Journal of Distance Education, 3(2), 1-6.

Nneji, L. M. (2002). "Study habits of Nigerian University Students", Nigerian Educational Research, Development Council, Abuja, Nigeria, Pages 490 - 495.

Parker, K. \& Parikh, S. (1999). Application of Prochaska's transtheoretical model to continuing medical education: From needs assessment to evaluation. Annals RCPSC (Royal College of Physicians and Surgeons of Canada), 32(2), 97-99.

Richards, L.G. (2001). "Further studies of study habits and study skills", Frontiers in Education Conference, 31st Annual, Volume 3, Page(s):S3D - S13, 10-13 Oct.

Rumelhart, D. (1980). Schemata: The Building Blocks of Cognition IN R.Spiro, B. Bruce and W. Brewer (1980).Theoretical Issues in Reading Comprehension. Hillside, N.J. Erbaum, PP.33-58

Trylong, V.L. (1987). Aptitude, attitudes and anxiety: a study of their relationships to achievement in the foreign language classroom. Unpublished Doctoral dissertation. Perdue University.

Tucker, G. R, Hamayan, E. \& Genesee, F.H. (1976). Affective, cognitive and social factors in second language acquisition. Canadian Modern Language Review, 32, 214-26.

Weiqiao Fan, Li-Fang Zhang. (2009), "Are achievement motivation and thinking styles related? A visit among Chinese university students", Learning and Individual Differences, Volume 19, Issue 2, Pages 299-303.

Young, D.J. (1986). The relationship between anxiety and foreign language oral proficiency ratings. Foreign Language Annals, 12, 439-48. 